\title{
SUPORTE MATERNO MEDIANTE O ABUSO SEXUAL INFANTIL: REVISÃO DE LITERATURA
}

\author{
Patricia Marafon \\ Universidade de Passo Fundo
}

Silvana Alba Scortegagna

Universidade de Passo Fundo

\begin{abstract}
Resumo
O suporte materno é fundamental para minimizar os efeitos traumáticos dos maustratos infantis. Objetivou-se com este estudo investigar como as mães se comportam frente à revelação do abuso sexual contra seus filhos. Com base nas diretrizes do guia Preferred Reporting Items for Systematic Reviews and Meta-Analyses PRISMA, foram selecionados artigos publicados entre 1995 e 2015, nas bases de dados SciELO, BVS e ScienceDirect, usando os descritores "maternal support", "disclosure", "child sexual abuse" e "psychological assessment", "suporte materno", "denúncia", "abuso sexual infantil", "avaliação psicológica". Identificaram-se 80 artigos, sendo 17 incluídos neste estudo. Diante da revelação do abuso: i) as mães oferecem apoio às filhas e necessitam de suporte para prestar auxílio; ii) o uso de álcool e drogas, as ideias suicidas e homicidas são fatores contribuintes para a falta de assistência das mães. 0 suporte materno em situação de abuso sexual está relacionado à rede de apoio psicossocial oferecido.
\end{abstract}

Palavras-chave: comportamento de ajuda; relações familiares; revelação; abuso da criança.

\section{SUPPORT BREAST BY SEXUAL ABUSE CHILD: A LITERATURE REVIEW}

\begin{abstract}
Breast support is critical to minimize the traumatic effects of child abuse. The objective of this study to investigate how mothers behave against the revelation of sexual abuse against children. Based on guidelines Preferred Reporting Items for Systematic Reviews and Meta-Analyses PRISMA selected articles published between 1995 and 2015, the SciELO databases, BVS and ScienceDirect, using the keywords "maternal support", "disclosure", "child sexual abuse" and "psychological assessment", "breast support", "complaint", "child sexual abuse", "psychological assessment". They identified 80 articles, 17 included in the study. At the revelation of abuse: i) mothers provide support and daughters need support to provide assistance; ii) the use of alcohol and drugs, suicidal and homicidal are contributing factors to the lack of care of mothers. Maternal support in sexual abuse situation is related to psychosocial support network offered.
\end{abstract}

Keywords: helping behavior; family relationships; revelation; child abuse. 


\title{
SOPORTE DE MAMA POR ABUSO SEXUAL INFANTIL: REVISIÓN DE LITERATURA
}

\begin{abstract}
Resumen
Apoyo a la lactancia es fundamental para minimizar los efectos traumáticos de abuso infantil. El objetivo de este estudio para investigar cómo las madres se comportan en contra de la revelación de abuso sexual contra los niños. Sobre la base de las directrices de informes preferidos Artículos para revisiones sistemáticas y metaanálisis de artículos publicados PRISMA seleccionado entre 1995 y 2015, las bases de datos SciELO, BVS y ScienceDirect, utilizando las palabras clave "apoyo materno", "divulgación", "sexual infantil abuso" y "evaluación psicológica", "apoyo a la lactancia", "queja", "abuso sexual infantil", "evaluación psicológica". Se identificaron 80 artículos, 17 incluidos en el estudio. En la revelación de abuso: i) las madres proporcionan apoyo e hijas necesitan apoyo para prestar asistencia; ii) el uso de alcohol y drogas, suicidio y homicidio son factores que contribuyen a la falta de cuidado de las madres. Apoyo materno en situación de abuso sexual está relacionada con la red de apoyo psicosocial ofrecido.
\end{abstract}

Palabras clave: conducta de ayuda; relaciones familiares; la revelación; abuso de niños.

\section{INTRODUÇÃO}

O abuso sexual contra crianças e adolescentes é um problema universal que atinge 120 milhões de mulheres com idade inferior a 20 anos (Stoltenborgh, Ijzendoorn, Euser, \& Bakermans-Kranenburg, 2011; Centro Regional de Informação das Nações Unidas, 2015). No Brasil, o abuso sexual é a $4^{\circ}$ violação mais recorrente contra crianças e adolescentes. No primeiro trimestre de 2015, foram denunciados 4.480 casos deste tipo de violência, o que representa $21 \%$ das mais de 20 mil demandas relacionadas às violações de direitos da população infanto-juvenil. Casos de abuso sexual estão presentes em $85 \%$ do total de denúncias (Ministério da Justiça e Cidadania, 2015), sendo o pai ou o padrasto da criança vitimizada o principal agressor, o que torna seus efeitos ainda mais nocivos (Ministério da Justiça e Cidadania, 2015; Scortegagna \& VillemorAmaral, 2009).

As consequências traumáticas do abuso sexual são devastadoras para o desenvolvimento físico, social e psíquico das vítimas (Arpini, Siqueira, \& Savegnago, 2015; Scortegagna \& Villemor-Amaral, 2009, 2013). Em curto prazo, os principais danos descritos pelas autoras incluem tendências suicidas, relações interpessoais disruptivas, isolamento, comportamento sexual inapropriado, problemas de aprendizagem e Transtorno de Estresse Pós Traumático (TEPT). Em longo prazo, o impacto do abuso sexual e a negligência podem ser associadas a depressão e a ansiedade (Maniglio, 2010, 2013).

A interação de fatores individuais, familiares e sociais de proteção, pode aumentar ou minimizar as consequências do abuso sexual supracitadas (Arpini et al., 2015; Scortegagna \& Villemor-Amaral, 2013). Especialmente no suporte materno, mediante a revelação do abuso sexual, este pode ser decisivo para determinar como um filho irá enfrentar os estressores provenientes da 
experiência abusiva e se conseguirá beneficiar-se da intervenção oferecida (Baia, Magalhães, \& Veloso, 2014).

Considerado um constructo multidimensional, o suporte materno consiste na ação protetora da mãe para evitar a continuidade dos maus-tratos, e na busca de intervenção apropriada (Smith et al., 2010). Uma resposta considerada suportiva se caracteriza pela preocupação empática e credibilidade às pessoas em situação de abuso sexual, enquanto que respostas não suportivas são caracterizadas pela culpabilização das pessoas vitimizadas, negação ou minimização do evento abusivo, e pelo abandono materno (Lamb \& Edgar-Smith, 1994).

A inexistência ou insuficiência do suporte materno tende a incrementar o efeito pervasivo do abuso sexual no desenvolvimento. Uma situação traumática provocada por uma pessoa de forte vínculo afetivo de proximidade e dependência, como a própria mãe ou os primeiros objetos de amor, tende a provocar danos mais sérios na constituição psíquica do que se a experiência fosse originária de uma relação impessoal (Briere, 2014). Além das falhas na constituição psíquica e dos danos já explicitados, pode levar às pessoas a terem mais dificuldades de revelar o abuso (Scortegagna \& Villemor-Amaral 2009, 2012) e a serem mais propensas a se envolver com o uso de drogas (Hadland et al., 2012).

Embora alguns estudos tenham demonstrado a associação entre o apoio materno e a adaptação infantil em casos de abuso sexual, há inconsistências entre os achados. As incongruências são justificadas basicamente pelo uso de testes de autorrelato e pela falta de evidências de validade dos instrumentos (Bick, Zajac, Rakton, \& Smith, 2014; Hadland et al., 2012). Diante do exposto, o objetivo deste estudo foi investigar como as mães se comportam frente à revelação do abuso sexual contra seus filhos, com base na literatura procedente de países desenvolvidos e em desenvolvimento.

\section{MÉTODO}

Esta revisão foi conduzida a partir das recomendações propostas no guia Preferred Reporting Items for Systematic Reviews and Meta-Analyses (PRISMA) (Moher et al., 2015) que facilita a elaboração de diretrizes clínicas, sendo extremamente útil para a tomada de decisão na área da saúde (Sheehan \& Lam, 2015). O PRISMA é uma diretriz que tem como objetivo ajudar autores a melhorar a qualidade do relato dos dados, composto de um checklist de 27 itens e um diagrama de fluxo de seleção de artigos (Moher et al., 2015). Para este estudo, utilizaram-se como critérios de inclusão os artigos publicados, exclusivamente, entre os anos de 1995 e 2015 que se relacionavam ao suporte oferecido pelas mães e/ou cuidadoras às crianças e adolescentes vítimas de abuso sexual. Excluíram-se estudos não condizentes com a temática proposta 
que tratavam, por exemplo, de mulheres vítimas de abuso sexual, avaliação do abusador e rede de apoio.

Realizou-se um levantamento, entre os meses de agosto de 2014 e outubro 2015, dos artigos completos publicados entre janeiro de 1995 e outubro de 2015, escritos em qualquer idioma. A razão da escolha desse período foi para abranger publicações de mais de uma década, considerada representativa da produção mais recente. A análise dos estudos envolvendo o desfecho pretendido foi efetuada nas bases de dados Scientific Electronic Library Online (SciELO), Biblioteca Virtual em Saúde (BVS) e ScienceDirect. Utilizaram-se como descritores: "maternal support", "disclosure", "child sexual abuse" e "psychological assessment", "suporte materno", "denúncia", "abuso sexual infantil", "avaliação psicológica".

Os títulos e resumos de todos os artigos identificados pela estratégia de busca foram avaliados independentemente pelos autores deste estudo. Todos os resumos que não forneceram informações suficientes sobre os critérios de inclusão e exclusão foram analisados na íntegra, sendo incluídos somente os que se relacionavam ao suporte oferecido pelas mães e/ou cuidadoras às crianças e adolescentes vítimas de abuso sexual, diante da revelação deste infortúnio. Os autores conduziram de forma individual a extração dos dados no que diz respeito às características metodológicas dos estudos, dos participantes, instrumentos empregados e desfecho. A Figura 1 apresenta o fluxograma da estratégia de busca dos artigos incluídos neste estudo de revisão.

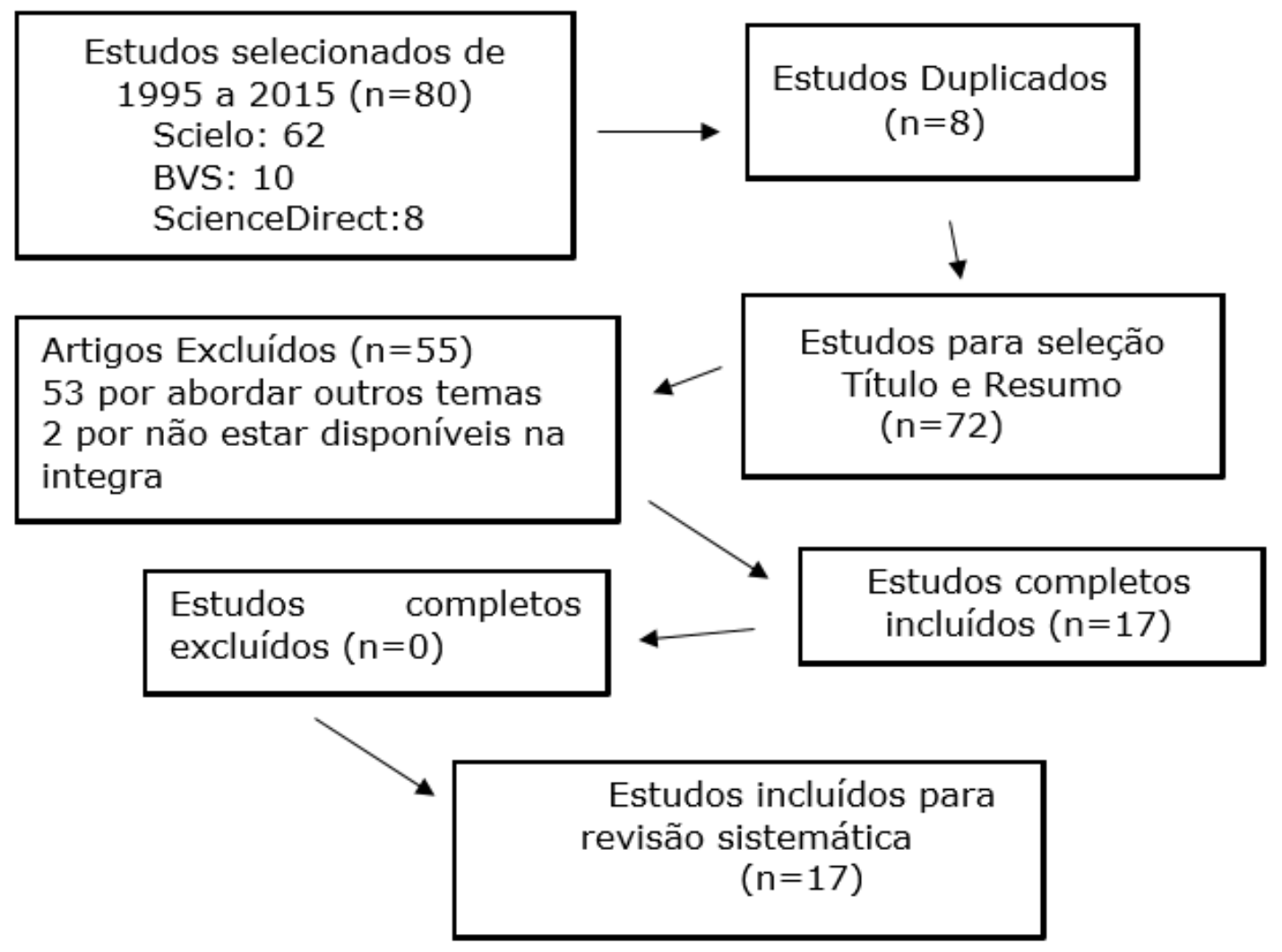

Figura 1. Fluxograma da estratégia de busca dos artigos 


\section{RESULTADOS}

A busca eletrônica em base de dados resultou na identificação inicial de 80 artigos. Foram localizados e eliminados oito artigos duplicados, resultando um total de 72 artigos. Desses, 55 foram excluídos após a análise dos títulos e resumos por não contemplarem a temática abordada ou por não apresentarem o texto na íntegra. A leitura e a análise dos 17 artigos restantes possibilitaram a verificação e a sistematização dos dados em vários elementos de investigação, separados em aspectos formais e de conteúdo. Na Tabela 1 são apresentados os artigos publicados sobre o apoio materno nos casos de abuso sexual infantil entre 1995 - 2015.

Tabela 1. Descrição das publicações sobre o apoio materno nos casos de abuso sexual infantil no período de 1995-2015

\begin{tabular}{|c|c|c|c|c|}
\hline Autor/Ano & Instrumentos & Objetivos & Participantes & Resultados \\
\hline $\begin{array}{l}\text { 1. Zajac et } \\
\text { al. } \\
(2015) \\
\text { EUA }\end{array}$ & $\begin{array}{c}\text { Entrevista } \\
\text { Estruturada e } \\
\text { Testes } \\
\text { Psicométricos }\end{array}$ & $\begin{array}{c}\text { Examinar as } \\
\text { relações do apoio } \\
\text { materno avaliado } \\
\text { por mães e seus } \\
\text { filhos }\end{array}$ & $\begin{array}{l}118 \text { díades de } \\
\text { mães e filhos }\end{array}$ & $\begin{array}{c}\text { O apoio materno } \\
\text { esteve relacionado } \\
\text { ao melhor ajuste } \\
\text { de pós-revelação } \\
\text { infantil }\end{array}$ \\
\hline $\begin{array}{l}\text { 2. Baía et } \\
\text { al. } \\
(2014) \\
\text { Brasil }\end{array}$ & $\begin{array}{c}\text { Entrevista } \\
\text { semiestrutura- } \\
\text { da }\end{array}$ & $\begin{array}{c}\text { Caracterizar o } \\
\text { suporte materno } \\
\text { às crianças } \\
\text { vítimas de abuso } \\
\text { sexual }\end{array}$ & 5 mães & $\begin{array}{c}\text { Falta de } \\
\text { credibilidade das } \\
\text { mães diante do } \\
\text { abuso não afetou } \\
\text { ações protetivas. } \\
\text { Discute-se a } \\
\text { importância da } \\
\text { intervenção } \\
\text { familiar }\end{array}$ \\
\hline $\begin{array}{l}\text { 3. Bick et } \\
\text { al. } \\
(2014) \\
\text { EUA }\end{array}$ & $\begin{array}{l}\text { Entrevista } \\
\text { clínica } \\
\text { estruturada }\end{array}$ & $\begin{array}{c}\text { Examinar a } \\
\text { convergência/dive } \\
\text { rgência, em mães } \\
\text { e crianças, de } \\
\text { relatórios de apoio } \\
\text { materno seguido à } \\
\text { revelação de } \\
\text { abuso sexual }\end{array}$ & $\begin{array}{c}120 \text { díades, } \\
60 \text { mães e } 60 \\
\text { crianças }\end{array}$ & $\begin{array}{c}\text { Houve } \\
\text { convergência nos } \\
\text { relatos das díades. } \\
\text { As mães } \\
\text { acreditaram na } \\
\text { revelação do abuso } \\
\text { e as vítimas foram } \\
\text { menos propensas } \\
\text { ao uso de tabaco e } \\
\text { drogas ilícitas }\end{array}$ \\
\hline $\begin{array}{l}\text { 4. Hébert } \\
\text { et al. } \\
\text { (2014) } \\
\text { Canadá }\end{array}$ & $\begin{array}{l}\text { Auto relatório e } \\
\text { Testes } \\
\text { Psicométricos }\end{array}$ & $\begin{array}{c}\text { Explorar o } \\
\text { potencial de } \\
\text { fatores pessoais, } \\
\text { familiares e } \\
\text { extrafamiliares } \\
\text { para a previsão de } \\
\text { sintomas de TEPT }\end{array}$ & $\begin{array}{c}6.540 \\
\text { adolescentes } \\
\text { entre } 14-18 \\
\text { anos de idade }\end{array}$ & $\begin{array}{c}\text { Meninas abusadas } \\
\text { sexualmente } \\
\text { apresentaram mais } \\
\text { TEPT. } \\
\text { Características do } \\
\text { abuso sexual } \\
\text { sofrido, resiliência, } \\
\text { suporte materno, } \\
\text { apoio dos pares } \\
\text { contribuíram para } \\
\text { sintomas de TEPT }\end{array}$ \\
\hline
\end{tabular}


Tabela 1. Continuação.

\begin{tabular}{|c|c|c|c|c|}
\hline Autor/Ano & Instrumentos & Objetivos & Participantes & Resultados \\
\hline $\begin{array}{l}\text { 5. Cyr, } \\
\text { McDuff \& } \\
\text { Hébert } \\
\text { (2013) } \\
\text { EUA }\end{array}$ & $\begin{array}{c}\text { Questionário e } \\
\text { Testes } \\
\text { Psicométricos }\end{array}$ & $\begin{array}{l}\text { Examinar como o } \\
\text { perfil psicológico } \\
\text { das mães in terfere } \\
\text { na sua capacidade } \\
\text { de sustentar os } \\
\text { filhos após a } \\
\text { divulgação do } \\
\text { abuso }\end{array}$ & 226 mães & $\begin{array}{c}\text { Gravidade dos at } \\
\text { cometidos, } \\
\text { estresse, } \\
\text { consequências d } \\
\text { abuso, maus- } \\
\text { tratos, qualidad } \\
\text { da relação mãe } \\
\text { filho, relacionarar } \\
\text { se ao apoio }\end{array}$ \\
\hline $\begin{array}{l}\text { 6. Rakow } \\
\text { et al. } \\
\text { (2011) } \\
\text { EUA }\end{array}$ & $\begin{array}{l}\text { Relatório, } \\
\text { Entrevista } \\
\text { Estruturada e } \\
\text { Testes } \\
\text { Psicométricos }\end{array}$ & $\begin{array}{c}\text { Analisar a } \\
\text { associação do } \\
\text { apoio materno } \\
\text { com sintomas } \\
\text { depressivos e } \\
\text { comportamentos } \\
\text { de delinquência } \\
\text { infantil }\end{array}$ & $\begin{array}{l}106 \text { diades, } \\
\text { mães e filhos }\end{array}$ & $\begin{array}{c}\text { Houve associaçã } \\
\text { entre os sintoma } \\
\text { depressivos } \\
\text { maternos e } \\
\text { comportamento: } \\
\text { delinquente err } \\
\text { crianças }\end{array}$ \\
\hline $\begin{array}{l}\text { 7. Smith et } \\
\text { al. } \\
(2010) \\
\text { EUA }\end{array}$ & $\begin{array}{c}\text { Entrevista; } \\
\text { Questionário e } \\
\text { Testes } \\
\text { Psicométricos }\end{array}$ & $\begin{array}{l}\text { Desenvolver um } \\
\text { auto relatório } \\
\text { válido para avaliar } \\
\text { o apoio materno } \\
\text { na divulgação do } \\
\text { abuso sexual } \\
\text { infantil }\end{array}$ & $\begin{array}{l}246 \text { diades de } \\
\text { mães e filhos }\end{array}$ & $\begin{array}{c}\text { Desenvolveu-se } \\
\text { auto relatório cor } \\
\text { medida de apoiı } \\
\text { materno com } \\
\text { propriedades } \\
\text { psicométricas }\end{array}$ \\
\hline $\begin{array}{c}8 . \\
\text { Amazonas } \\
\text { et al. } \\
\text { (2009) } \\
\text { Brasil }\end{array}$ & $\begin{array}{c}\text { Entrevistas } \\
\text { abertas }\end{array}$ & $\begin{array}{l}\text { Compreender a } \\
\text { relação entre } \\
\text { mães e filhas após } \\
\text { a descoberta do } \\
\text { abuso sexual } \\
\text { incestuoso sof rido } \\
\text { pela criança }\end{array}$ & $\begin{array}{c}4 \text { mães, entre } \\
23-35 \text { anos } \\
\text { que } \\
\text { denuncia ram } \\
\text { o abuso } \\
\text { sexual } \\
\text { incestuoso } \\
\text { sof rido pelas } \\
\text { filhas }\end{array}$ & $\begin{array}{c}\text { Dificuldade de } \\
\text { estabelecer conta } \\
\text { físico com a } \\
\text { criança, } \\
\text { agressividade d } \\
\text { filha dirigida à } \\
\text { genitora, } \\
\text { sof rimento da m } \\
\text { diante do } \\
\text { comportamento } \\
\text { filha }\end{array}$ \\
\hline $\begin{array}{c}9 . \\
\text { Carvalho } \\
\text { et al. } \\
\text { (2009) } \\
\text { Brasil } \\
\end{array}$ & $\begin{array}{c}\text { Entrevista } \\
\text { semiestruturad } \\
\text { a }\end{array}$ & $\begin{array}{c}\text { Apreender a } \\
\text { percepção de } \\
\text { mães de filhas } \\
\text { vítimas de abuso } \\
\text { sexual }\end{array}$ & 10 mães & $\begin{array}{c}\text { Mães vivenciara } \\
\text { sentimentos de } \\
\text { dor, revolta e } \\
\text { impotência }\end{array}$ \\
\hline $\begin{array}{l}\text { 10. Santos } \\
\text { \& Dell'aglio } \\
\text { (2009) } \\
\text { Brasil }\end{array}$ & $\begin{array}{c}\text { Entrevistas } \\
\text { individuais e } \\
\text { semiestrutura- } \\
\text { da }\end{array}$ & $\begin{array}{l}\text { Investigar como } \\
\text { mães de meninas } \\
\text { abusadas } \\
\text { sexualmente } \\
\text { reagem diante do } \\
\text { conhecimento do } \\
\text { abuso }\end{array}$ & $\begin{array}{c}10 \text { mã es, } \\
\text { entre } 24-40 \\
\text { anos de idade }\end{array}$ & $\begin{array}{c}\text { Mães acreditaram } \\
\text { denunciaram o } \\
\text { abuso, mas ner } \\
\text { todas afasta ran } \\
\text { suas filhas do } \\
\text { abusador }\end{array}$ \\
\hline
\end{tabular}


Tabela 1. Continuação.

\begin{tabular}{|c|c|c|c|c|}
\hline Autor/Ano & Instrumentos & Objetivos & Participantes & Resultados \\
\hline $\begin{array}{c}11 . \\
\text { Coohey \& } \\
\text { O'leary } \\
(2008) \\
\text { Austrália }\end{array}$ & $\begin{array}{l}\text { Entrevista e } \\
\text { Testes } \\
\text { Psicométricos }\end{array}$ & $\begin{array}{l}\text { Compreender por } \\
\text { que mães não } \\
\text { protegem seus } \\
\text { filhos depois da } \\
\text { revelação do } \\
\text { abuso }\end{array}$ & $\begin{array}{c}85 \text { mães, } 48 \\
\text { que } \\
\text { protegerem } \\
\text { seus filhos e } \\
37 \text { que não o } \\
\text { fizeram }\end{array}$ & $\begin{array}{l}\text { Mães não vítima } \\
\text { de violência } \\
\text { doméstica foran } \\
\text { mais propensas } \\
\text { proteger seus filh }\end{array}$ \\
\hline $\begin{array}{c}12 . \\
\text { Santos, } \\
\text { Dell'aglio } \\
\text { (2008) } \\
\text { Brasil }\end{array}$ & Estudo teórico & $\begin{array}{c}\text { Discutir as } \\
\text { características de } \\
\text { mães de crianças } \\
\text { vítimas de abuso } \\
\text { sexual, como } \\
\text { ajustamento } \\
\text { emocional, } \\
\text { multigeracionalida } \\
\text { de e reações } \\
\text { frente à revelação }\end{array}$ & - & $\begin{array}{c}\text { As mães } \\
\text { apresentaram du } \\
\text { posições distinta } \\
\text { cúmplice e } \\
\text { protetora. A } \\
\text { postura adotad; } \\
\text { dependeu da } \\
\text { história, e das } \\
\text { representações } \\
\text { sobre a familia }\end{array}$ \\
\hline $\begin{array}{l}\text { 13. Leifer } \\
\text { et al. } \\
\text { (2003) } \\
\text { EUA }\end{array}$ & $\begin{array}{l}\text { Entrevistas } \\
\text { Semiestrutu- } \\
\text { rada e Testes } \\
\text { Psicométricos }\end{array}$ & $\begin{array}{c}\text { Avaliar as relações } \\
\text { de apego } \\
\text { materno, e as } \\
\text { percepções } \\
\text { infantis de apoio } \\
\text { matemo }\end{array}$ & $\begin{array}{l}96 \text { crianças } \\
\text { vítimas de } \\
\text { abuso sexual } \\
\text { e } 100 \text { crianças } \\
\text { não vítimas }\end{array}$ & $\begin{array}{l}\text { Mães com estilo } \\
\text { de apego insegu } \\
\text { relata ram mais } \\
\text { problemas globa } \\
\text { de comportamen } \\
\text { em seus filhos }\end{array}$ \\
\hline $\begin{array}{l}\text { 14. Cyr et } \\
\text { al. } \\
(2002) \\
\text { EUA }\end{array}$ & $\begin{array}{l}\text { Questionário; } \\
\text { Entrevista } \\
\text { Semiestruturad } \\
\text { a e Testes } \\
\text { Psicométricos }\end{array}$ & $\begin{array}{l}\text { Analisar preditores } \\
\text { de apoio materno }\end{array}$ & $\begin{array}{c}20 \\
\text { adolescentes } \\
\text { entre } 12 \text { a } 17 \\
\text { anos, e suas } \\
\text { mães }\end{array}$ & $\begin{array}{c}\text { Foram preditore } \\
\text { de apoio: admiss } \\
\text { da culpa pelo } \\
\text { agressor, } \\
\text { comprovação d, } \\
\text { abuso, relação cc } \\
\text { o perpetrador } \epsilon \\
\text { status profission } \\
\text { materno }\end{array}$ \\
\hline $\begin{array}{l}\text { 15. Leifer } \\
\text { et al. } \\
\text { (2001) } \\
\text { EUA }\end{array}$ & $\begin{array}{l}\text { Entrevistas e } \\
\text { Testes } \\
\text { Psicométricos }\end{array}$ & $\begin{array}{c}\text { Investigar a } \\
\text { história familiar, } \\
\text { relações de apego } \\
\text { e experiências } \\
\text { abusivas de } \\
\text { familias de } \\
\text { crianças abusadas }\end{array}$ & $\begin{array}{c}61 \text { mães } \\
\text { provedoras de } \\
\text { suporte e } 38 \\
\text { mães } \\
\text { abusivas; } 52 \\
\text { avós, } 33 \text { eram } \\
\text { as mães de } \\
\text { filhas que } \\
\text { prestaram } \\
\text { apoio e } 19 \\
\text { eram mães } \\
\text { daquelas que } \\
\text { não presta ram } \\
\text { suporte }\end{array}$ & $\begin{array}{c}\text { História de relaçõ } \\
\text { de apego em } \\
\text { conflituadas entı } \\
\text { avó/mãe e } \\
\text { mãe/filho, e men } \\
\text { apoio prestado pı } \\
\text { avó para a crianç } \\
\text { Mães abusivas } \\
\text { apresentaram } \\
\text { comportamento: } \\
\text { criminosos e abu } \\
\text { de substâncias }\end{array}$ \\
\hline
\end{tabular}


Tabela 1. Continuação.

\begin{tabular}{|c|c|c|c|c|}
\hline Autor/Ano & Instrumentos & Objetivos & Participantes & Resultados \\
\hline $\begin{array}{c}16 . \\
\text { Paredes et } \\
\text { al. } \\
(2001) \\
\text { EUA }\end{array}$ & Entrevistas & $\begin{array}{c}\text { Explorar como a } \\
\text { história e o } \\
\text { funcionamento } \\
\text { das mães afetam } \\
\text { a recuperação das } \\
\text { crianças } \\
\text { vitimiza das }\end{array}$ & $\begin{array}{c}67 \text { mães e } \\
\text { suas filhas } \\
\text { abusadas } \\
\text { sexualmente }\end{array}$ & $\begin{array}{c}\text { Experiências } \\
\text { passadas das mã } \\
\text { foram associada } \\
\text { ao comportamen } \\
\text { dos filhos vítima } \\
\text { de abuso sexua }\end{array}$ \\
\hline $\begin{array}{c}17 . \\
\text { Hiebert- } \\
\text { Mu rphy } \\
\text { (1998) } \\
\text { Canadá }\end{array}$ & $\begin{array}{l}\text { Questionário; } \\
\text { Entrevista } \\
\text { Estruturada e } \\
\text { Testes } \\
\text { Psicométricos }\end{array}$ & $\begin{array}{c}\text { Investigar os } \\
\text { fatores } \\
\text { psicossociais } \\
\text { relacionados à } \\
\text { angústia das mães } \\
\text { após a divulgação } \\
\text { do abuso }\end{array}$ & 102 mães & $\begin{array}{l}\text { O sof rimento da } \\
\text { mães após a } \\
\text { revelação do abu } \\
\text { sexual das filha: } \\
\text { esteve relaciona، } \\
\text { a história pessoi } \\
\text { de abuso sexua } \\
\text { infantil }\end{array}$ \\
\hline
\end{tabular}

Observa-se na Tabela 1 que entre os estudos relativos ao período de 1995 a 2015, doze foram publicados entre os anos 2006 e 2015 (1, 2, 3, 4, 5, 6, 7, 8, 9, 10, 11, 12) e cinco entre os anos de 1995 e 2005 (13, 14, 15, 16, 17). Nos últimos 10 anos (2005-2015) o número de publicações em relação ao suporte materno na revelação do abuso sexual, predominantemente de meninas, aumentou, sendo a maior parte conduzida em países "desenvolvidos" (EUA, Canada e Austrália), utilizando-se de amostras mais extensas, chegando a 6.540 casos (4), o que confere uma compreensão mais generalizada dos achados. As pesquisas procedentes de países em desenvolvimento foram originárias fundamentalmente do Brasil (2-8-9-10-12), com amostras reduzidas e resultados mais circunscritos.

Quanto aos objetivos, além de todos os estudos investigarem o apoio materno prestado às pessoas em situação de abuso sexual, alguns examinaram as características das mães, das vítimas, as particularidades da revelação (2-35-9-10-11-13-14), a história familiar (13-15-16), e o histórico materno de abuso sexual (16-17). O uso de substâncias, como álcool e drogas por parte das mães e das vítimas também foi objeto de investigação (3-15-16).

Os participantes foram recrutados em centros de apoio para pessoas em situação de abuso sexual (5-7-11-13-14) e em hospitais (13-15-16-17). A maior parte dos estudos não utilizou critérios de exclusão para selecionar os participantes (4-5-7-11-13-14-15-16-17), e os que utilizaram (1-2-3-6-8), consideraram para a pesquisa crianças vítimas de abuso sexual envolvendo contato físico (caricias e penetração), e mães que não foram cúmplices da violência e estavam em atendimento em centros de apoio há três anos (1-3-67). 
Os estudos foram realizados por meio de entrevistas semiestruturadas, (12-3-7-8-9-10-11-13-14-15-16-17), e instrumentos psicométricos (1-4-5-6-7-1113-14-15-16-17), como Child Behavior Checklist - CBCL (1-5-6-7-11-16), Parental Reaction to Abuse Disclosure Scale (5-13-15-16), Maternal Self-Report Support Questionnaire-MSSQ (1-6-7), Trauma Symptom Checklist for childrenTSCC (1-15-16), relatórios (4-6-16) e questionários (7-14-17). A eleição de instrumentos psicométricos visou responder aos estudos quantitativos conduzidos em países desenvolvidos, que perfaz a maior parte das pesquisas elencadas. Observa-se, ainda, a falta de instrumentos validados para a população brasileira para responder às demandas de avaliação do suporte materno.

\section{DISCUSSÃO}

Ao atingir o objetivo de investigar como as mães de pessoas em situação de abuso sexual se comportam diante da revelação, a partir da literatura, este estudo trouxe contribuições relevantes. A maior parte das mães avaliadas pelos estudos dos países em desenvolvimento, dizem oferecer suporte às filhas, frente à revelação do abuso sexual, e afastá-las do contato com o abusador $(1,3,5,11)$. Embora esses resultados sejam promissores, o suporte materno foi mensurado com medidas de autorrelato como o Parental Reaction to Abuse Disclosure Scale e o Maternal Self-Report Support Questionnaire-MSSQ, que sofrem a interferência de fatores de desejabilidade social, o que pode ter influenciado nas respostas das mães. Pesquisas prévias mostram que as mães raramente endossam opções de respostas socialmente inadequadas (Mannarino \& Cohen, 1996).

Outra questão a ser considerada é que o apoio materno é um constructo multidimensional (Smith et al., 2010) o que limita a abrangência dos resultados para todas as dimensões do conceito. Para os autores referidos, na maior parte dos estudos, as variáveis avaliadas incluíram uma ou mais formas de ação protetora como: separação da criança do agressor e 0 apoio verbal/emocional/empático e/ou a crença na revelação do abuso. Para melhor exemplificar, o estudo que avaliou a convergência e divergência sobre os relatos de suporte materno após a denúncia do abuso sexual (3) perguntou às mães "quando você soube do abuso, acreditou que ele aconteceu conforme foi descrito?" e à criança "quanto sua mãe acreditou no que você contou sobre o abuso?". A investigação não contemplou outros domínios do suporte materno como proporcionar apoio emocional contínuo, proteger à criança do abusador ou de situações que ameaçassem a sua segurança, oferecendo serviços profissionais.

Apesar dos achados inconclusivos, alguns estudos demonstram os fatores que ajudam e os que dificultam a capacidade das mães para oferecer suporte. 
Dentre os principais preditores a identidade do perpetrador e a sua relação com a mãe, tem influência significativa sobre o apoio materno à pessoa em situação de abuso sexual (Cyr et al., 2002). No caso do ofensor ser o pai ou o padrasto e da mãe residir com ele, ela é menos propensa a responder à denúncia do abuso com apoio. Aliado a isso, mães financeiramente independentes são mais propensas a oferecer suporte, (Cyr et al. 2002; Leifer, Kilbane, \& Grossman, 2001) e na perspectiva dos adolescentes, a confirmação de abuso por parte do autor e de outras fontes como irmãos, amigos, profissionais, são preditores decisivos de apoio materno (Cyr et al., 2002). A admissão de culpa pelo autor parece aliviar uma dúvida sobre o papel do adolescente na sua própria vitimização, o que auxilia as mães a responderem de uma forma mais encorajadora. Em relação ao tempo do conhecimento do abuso sexual, mães que tinham conhecimento do abuso sexual há um ano ou menos, acreditam e protegem melhor seus filhos do que àquelas que sabiam há mais de um ano (Coohey \& O'Leary, 2008).

O suporte materno pode estar relacionado ao uso de substâncias, ou seja, mães que cresceram em famílias com o uso de substâncias, e que usam álcool e drogas, são mais predispostas a terem crianças com história de vitimização sexual e a não serem capazes de apoiar seus filhos diante da violência, o que contribui para maior agressividade no comportamento destes (Paredes, Leifer, \& Kilbane, 2001). Constata-se assim, que mães livres de adições são mais compreensivas e empáticas, e dão liberdade para as crianças expressarem como se sentem em relação a experiência sexual abusiva, o que diminui condutas externalizantes, como a agressividade. Corroborando esses achados, verifica-se que crianças que contam com um ambiente acolhedor, conseguem melhor processar a experiência traumática do abuso (Briere, 2014; Scortegagna \& Villemor-Amaral, 2009, 2012, 2013) e mostram maior possibilidade de recuperação (Baia et al., 2014).

Além do abuso de substâncias, mães que apresentam problemas com a lei, relacionamentos disfuncionais e conflitados com seus parceiros, incluindo violência doméstica (Bick et al., 2014; Leifer et al., 2001; Paredes et al., 2001) acreditam menos no relato de seus filhos, e oferecem menos apoio. É importante salientar, o quanto isso deflagra a necessidade de prover assistência terapêutica e psicossocial às mães, aos perpetradores de violência, para que possam romper com a violência intrafamiliar, prevenir à revitimização e auxiliar na recuperação da criança.

Indo um pouco mais além e incluindo a necessidade de assistência à família extensa, um único estudo avaliou a multigeracionalidade de três famílias de vítimas de abuso sexual, e constatou conflitos relacionados ao suporte oferecido às crianças que sofreram abuso sexual (Leifer et al., 2001). Os autores demostraram que as avós que qualificam as relações com seus filhos como 
negativas oferecem menos apoio aos seus netos e àquelas que proporcionam maior apoio foram mais propensas a defender seus netos na divulgação.

Legitimando quase integralmente esses resultados, nas pesquisas realizadas no Brasil verifica-se, em um primeiro momento, há falta de credibilidade no abuso sexual sofrido pelos filhos, mas que não impede à tomada de ações protetivas (Carvalho, Galvão, \& Cardoso, 2009). Algumas mães que acreditaram no relato dos filhos, não tomam todas as medidas protetivas no sentido de afastar a vítima do abusador. A relutância das mães em denunciar o abuso associa-se ao medo das ameaças do abusador, ao temor de perder a família constituída e, do que os familiares e a sociedade possam pensar sobre a qualidade dos seus cuidados (Santos \& Dell'aglio, 2008).

Os sentimentos das mães em relação ao abuso sexual de seus filhos incluíram dor, revolta e impotência e, especificamente, quanto ao abusador, variam de raiva e culpa (Amazonas, Oliveira, \& Melo, 2009; Carvalho et al., 2009; Santos \& Dell'aglio, 2009) por terem confiado neles ou por não terem conseguido proteger seus filhos (Santos \& Dell'aglio, 2009). O sentimento de culpa torna-se maior naquelas que também foram vítimas de abuso sexual na infância, que entendem que poderiam ter evitado o abuso ou, ao menos, imaginar que a violência poderia se repetir (Carvalho et al., 2009; Santos \& Dell'aglio, 2009). Para essas mães, pensar sobre suas próprias histórias é muito doloroso, mas diante do abuso sexual de seus filhos, percebem que devem agir diferentemente das práticas recebidas das suas próprias mães, para romper com o círculo abusivo (Cyr, McDuff, \& Hébert, 2013; Santos \& Dell'aglio, 2009). Observa-se a culpa como grande responsável pelo sofrimento das mães, arraigada a um elemento cultural que idealiza uma mãe perfeita em todos os momentos. Em face a estes sentimentos, as mães podem desenvolver ideias suicidas e homicidas e, consequentemente, prover um menor apoio às pessoas vítimas de abuso sexual (Carvalho et al., 2009), como também observado nos estudos internacionais.

Diante do abuso sexual infantil extrafamiliar as mães tem necessidade de indícios complementares para dar credibilidade ao relato de suas filhas, utilizando-se de questionamentos às pessoas em situação de abuso sexual, com o objetivo de conhecer a identidade do agressor e se houve histórico de outras experiências abusivas. Estes casos de abuso extrafamiliar estão associados a um suporte mais efetivo em comparação a contextos de abuso intrafamiliar. Os estudos apontam que as mães buscam medidas protetivas afastando seus filhos do contato com o agressor, realizam a denúncia e procuram acompanhamento psicossocial para às vítimas (Baia et al., 2014; Carvalho et al., 2009).

Em casos de abuso sexual infantil, pode-se perceber o receio ou a não revelação do fato ocorrido para outros membros da família. Pode-se observar sentimentos de medo nas mães de serem julgadas pela comunidade diante da violência perpetrada (Baia et al., 2014). Segundo estes autores, a descoberta do 
abuso sexual gera dificuldades pessoais e sociais, mas mesmo assim, as mães buscam acentuar suas práticas maternas e restabelecer a relação de confiança com a vítima, por meio do diálogo e assistência profissional.

Quando as mães não reconhecem a ocorrência do abuso sexual, não conseguem perceber os riscos que a criança corre e a proteção das vítimas se fragiliza. Desse modo, seus filhos podem ficar mais vulneráveis à violência (Amazonas et al., 2009). Nos casos de abuso sexual infantil ocorrem dificuldades nas mães para se relacionarem com seus filhos de modo afetivo e pode-se observar o rompimento dos vínculos entre os pais da vítima. É possível verificar as dificuldades das mulheres em viverem novos relacionamentos por temor de, novamente, atravessar uma situação de violência familiar (Amazonas et al., 2009).

Desta forma, o apoio que as vítimas recebem de suas mães/cuidadoras está relacionado com a adaptação da criança, o que representa um componente vital no processo de recuperação dos danos físicos e mentais, resultantes da violência sofrida, tanto em longo quanto em curto prazo (Bick et al., 2014). Receber apoio emocional das mães contribui para que as vítimas tenham maior liberdade de expressar os sentimentos relativos ao abuso, diminuindo, assim, a vivência traumática (Leifer, Kilbane, \& Skolnick, 2003; Rakow, Smith, Begle, \& Ayer, 2011). Auxilia a enfrentar os sentimentos de ansiedade, TEPT, dissociação, depressão, raiva e também preocupações sexuais (Bick et al., 2014; Cyr et al., 2013; Hébert, Lavoie, \& Blais, 2014; Leifer et al., 2003; Zajac, Ralston, \& Smith, 2015), dentre outros.

\section{CONSIDERAÇÕES FINAIS}

Baseado nos resultados dos escassos estudos elencados nesta revisão de literatura verifica-se a existência de diferenças substanciais entre a abordagem metodológica utilizada nas pesquisas realizadas nos países desenvolvidos e em desenvolvimento. Entretanto, pode-se dizer que em ambos os países, as mães acreditam no relato de seus filhos, buscam indícios complementares para dar credibilidade à denúncia, especialmente quando se trata do abuso contra filhos adolescentes, e necessitam de suporte para prestar auxílio. Observa-se que mães que fazem uso de drogas ilícitas ou licitas, tendem a não conseguir prestar apoio apropriado para seus filhos, na revelação do abuso sexual sofrido, o que aponta a necessidade de assistência profissional especializada às mães.

Um desafio no seguimento de pesquisas tanto nos países desenvolvidos quanto em desenvolvimento, é a utilização de outros instrumentos de investigação, além dos de autorrelato. Além disso, em se tratando de estudos brasileiros, estes poderiam utilizar amostras mais representativas e investigar 
em que medida às mães recebem apoio psicossocial para serem capazes de ampararem seus filhos vitimizados.

Por fim, uma rede de apoio psicossocial para o suporte às mães é de fundamental importância para minimizar às consequências danosas do abuso sexual, combater a (re) vitimização, e a perpetuação da violência transgeracional. Esta revisão pode ser um recurso útil para pesquisadores, profissionais que se dedicam a estudar e a atender esta população e, também, fortalecer políticas públicas interessadas em tomar por base às evidências aqui relacionadas para direcionar suas ações.

\section{REFERÊNCIAS}

*Amazonas, M. C. L. A., Oliveira, P. A., \& Melo, L. M. M. B. (2009). Repercussões do abuso sexual incestuoso sobre a relação mãe $X$ filha. Psicologia em Revista, 15(3), 82-100. doi:10.5752/P.1678-9563.2009V15N3P82

Arpini, D. M., Siqueira, A. C., \& Savegnago, S. D. O. (2012). Trauma psíquico e abuso sexual: o olhar de meninas em situação de vulnerabilidade. Psicologia: Teoria e Prática, 14(2), 88-101

*Baia, P. A. D., Magalhães, C. M. C., \& Veloso, M. M. X. (2014). Caracterização do suporte materno na descoberta e revelação do abuso sexual infantil. Temas em Psicologia, 22(4), 691-700. doi:10.9788/TP2014.4-02

*Bick, J., Zajac, K., Rakton, M. E., \& Smith, D. (2014). Convergence and divergence in reports of maternal support following childhood sexual abuse: Prevalence and associations with youth psychosocial adjustment. Child Abuse \& Neglect, 38(3), 479-487. doi:10.1016/j.chiabu.2013.11.010

Briere, J. (2004). Psychological assessment of adult posttraumatic states: Phenomenology, diagnosis, and measurement (2nd ed.). Washington, DC: American Psychological Association.

*Carvalho, Q. C. M., Galvão, M. T. G., \& Cardoso, M. V. L. M. L. (2009). Abuso sexual infantil: Percepção de mães em face do abuso sexual de suas filhas. Revista Latino-Americano de Enfermagem, 17(4), 501-6. doi: 10.1590/S0104-11692009000400011

Centro Regional de Informação das Nações Unidas (2015). Não basta saber e estar preocupado: as meninas têm de ser empoderadas para acabarmos de vez com a violência. Recuperado de http://www.unric.org/pt/actualidade/31636-nao-basta-saber-e-estarpreocupado-as-meninas-tem-de-ser-empoderadas-para-acabarmos-de-vezcom-a-violencia 
*Coohey, C., \& O'Leary, P. (2008). Mothers' protection of their children after discovering they have been sexually abused: an information-processing perspective. Child Abuse \& Neglect, 32(2), 245-59. doi: 10.1016/j.chiabu.2007.06.002

*Cyr, M., McDuff, P., \& Hébert, M. (2013). Support and profiles of nonoffending mothers of sexually abused children. Journal of Child Sexual Abuse, 22(2), 209-30. doi: 10.1080/10538712.2013.737444

*Cyr, M., Wright, J., Toupin, J., Oxman-Martinez, J., McDuff, P., \& Thériault, C. (2002). Predictors of maternal support: the point of view of adolescent victims of sexual abuse and their mothers. Journal of Child Sexual Abuse, 12(1), 39-65. doi:10.1300/J070v12n01_03

Hadland, S. E., Werb, D., Kerr, T., Fu, E., Wang, H., ..., \& Wood, E. (2012). Childhood sexual abuse and risk for initiating injection drug use: a prospective cohort study. Preventive Medicine, 55(5), 500-504. doi: 10.1016/j.ypmed.2012.08.015

*Hébert, M., Lavoie, F., \& Blais, M. (2014). Post-traumatic stress disorder/PTSD in adolescent victims of sexual abuse: resilience and social support as protection factors. Ciência Saúde Coletiva, 19(3), 685-694. doi: $10.1590 / 1413-81232014193.15972013$

*Hiebert-Murphy, D. (1998). Emotional distress among mothers whose children have been sexually abused: The role of a history of child sexual abuse, social support, and coping. Child Abuse \& Neglect, 22(5), 423-35.

Lamb, S., Edgar-Smith, S. (1994). Aspects of disclosure: Mediators of outcome of childhood sexual abuse. Journal of Interpersonal Violence, 9(3), 307-326. doi: $10.1177 / 088626094009003002$

*Leifer, M., Kilbane, T., \& Grossman, G. (2001). A three-generational study comparing the families of supportive and unsupportive mothers of sexually abused children. Child Maltreatment, 12(1), 39-65

*Leifer, M., Kilvante, T., \& Skolnick, L. I. (2003). Relationships between maternal adult attachment security, child perceptions of maternal support, and maternal perceptions of child responses to sexual abuse. Journal of Child Sexual Abuse, 11(3), 107-24

Maniglio, R. (2010). Child sexual abuse in the etiology of depression systematic review of reviews. Depression and Anxiety, 27(7), 631-642

Maniglio, R. (2013). Child sexual abuse in the etiology of anxiety disorders: a systematic review of reviews. Trauma Violence Abuse, 14(2), 96-112. doi: $10.1177 / 1524838012470032$

Mannarino, A.P., \& Cohen, J. A. (1996) Family-related variables and psychological symptom formation in sexually abused girls. Journal of Child Sexual Abuse, 5, 105-120. http://dx.doi.org/10.1300/J070v05n01_06 
Ministério da Justiça e Cidadania. Secretaria Especial de Direitos Humanos (2015). Disque 100: Quatro mil denúncias de violência sexual contra crianças e adolescentes foram registradas no primeiro trimestre de 2015. Recuperado de http://www.sdh.gov.br/noticias/2015/maio/disque-100quatro-mil-denuncias-de-violencia-sexual-contra-criancas-e-adolescentesforam-registradas-no-primeiro-trimestre-de-2015

Moher, D., Shamseer, L., Clarke, M., Ghersi, D., Liberati, A., ..., \& Prisma-P Group (2015). Preferred reporting items for systematic review and metaanalysis protocols (PRISMA-P) 2015 statement. Systematic Reviews, 4(1), 1-19. doi:10.1186/2046-4053-4-1

Molnar, B. E., Buka, S. L., \& Kessler, R. C. (2001). Child sexual abuse and subsequent psychopathology: Results from the National Comorbidity Survey. American Journal of Public Health, 91(5), 753-760.

*Paredes, M., Leifer, M., \& Kilbane, T. (2001). Maternal variables related to sexually abused children's functioning. Child Abuse \& Neglect, 25(9), 11591176

*Rakow, A., Smith, D., Begle, A. M., \& Ayer, L. (2011). The association of maternal depressive symptoms with child externalizing problems: The role of maternal support following child sexual abuse. Journal of Child Sexual Abuse, 20(4), 467-80. doi:10.1080/10538712.2011.588189

*Santos, S.S., \& Dell'aglio, D. D. (2008). Compreendendo as mães de crianças vítimas de abuso sexual: Ciclos de violência. Estudos em Psicologia, 25(4), 595-606. doi:10.1590/S0103-166X2008000400014.

*Santos, S. S., \& Dell'aglio, D. D. (2009). Revelação do abuso sexual infantil: reações maternas. Psicologia: Teoria e Pesquisa, 25(1), 85-92. http://dx.doi.org/10.1590/S0102-37722009000100010

Scortegagna, A. S., Villemor-Amaral, A. E. (2009). Autopercepção no Rorschach de vítimas de abuso sexual infantil. Psico, 40(3), 328-336

Scortegagna, A. S., \& Villemor-Amaral, A. E. (2012). The use of the Rorschach method in the investigation of sexual abuse of children. Paidéia, 22(52), 271-280. doi:10.1590/S0103-863X2012000200013

Scotergagna, A. S., \& Villemor-Amaral, A. E. (2013). Traumatic loss and helplessness: qualitative analysis of responses in the Rorschach. Psico USF, 18(1), 1-12. doi:10.1590/S1413-82712013000100002

Sheehan, M. C., \& Lam, J. (2015) Use of systematic review and meta-analysis in environmental health epidemiology: a systematic review and comparison with guidelines. Pharmacology \& Toxicology, 2, 272-283. doi: $10.1007 /$ s40572-015-0062-z 
*Smith, D. W., Sawyer, G. K., Jones, L. M., Cross, T., McCart, M. R., \& Ralston, M. E. (2010). Mother reports of maternal support following child sexual abuse: Preliminary psychometric data on the maternal self-report support questionnaire (MSSQ). Child Abuse \& Neglect, 10(3), 784-92. doi:10.1016/j.chiabu.2010.02.009.

Stoltenborgh, M., Van Ijzendoorn, M. H., Euser, E. M., \& Bakermans-Kranenburg, M. J. (2011). A global perspective on child sexual abuse: Meta-analysis of prevalence around the world. Child Maltreatment, 16(2), 79-101.

*Zajac, K., Ralston, M. E., Smith, D. W. (2015). Maternal support following childhood sexual abuse: Associations with children's adjustment postdisclosure and at 9-month follow-up. Child Abuse \& Neglect, 44, 66-75. doi: $10.1016 /$ j.chiabu.2015.02.011

* Estudos incluídos na revisão de literatura.

Sobre as autoras

Patricia Marafon é Psicóloga formada pela Universidade de Passo Fundo-RS. Email: patimarafon.psi@gmail.com

Silvana Alba Scortegagna é Psicóloga, doutora em Psicologia pela Universidade de São Francisco, Itatiba-SP, docente do Programa de Pós-Graduação em Envelhecimento Humano da Universidade de Passo Fundo-RS. E-mail: silvanalba@upf.br

Recebido em: 31/05/2016

Revisado em: 19/09/2016

Aceito em: 26/10/2016 